\title{
A role for auto-immunity in chronic rhinosinusitis? Lessons learned from sub-epidermal bullous disorders of the skin
}

\author{
Philippe Lefrançois ${ }^{1}$, Hugo Chapdelaine ${ }^{2}$, Benoît Côté ${ }^{2}$ and Martin Desrosiers ${ }^{2,3^{*}}$
}

\begin{abstract}
Chronic rhinosinusitis (CRS) is a frequent chronic condition, which has origins in complex interactions between genetic, immunological and microbial factors. The role of auto-immunity in CRS remains unclear, although recent studies have started to emerge in CRS patient refractory to maximal medical management. We discuss the possible auto-immunity link between CRS and other skin diseases, in particular acquired bullous dermatoses, and review the current evidence. We raise additional considerations for auto-immunity from both research and clinical standpoints.
\end{abstract}

Keywords: Chronic rhinosinusitis, Auto-immunity, lgE, Blistering skin disorders, Bullous pemphigoid

\section{Background}

Chronic rhinosinusitis (CRS) is a common condition affecting $\sim 13 \%$ of the US adult population, a prevalence higher than that of diabetes [1]. The productivity loss accounting from CRS amounts to $\$ 13$ billion USD [2], with total disease burden estimated around $\sim \$ 60$ billion USD [3]. Of particular interest are patients with refractory CRS, for whom maximal medical therapy provides at most marginal benefits. Refractory CRS patients are currently managed with multiple sinus surgeries, yet they still experience recurrent exacerbations requiring antibiotics.

The etiology of CRS is believed to be multifactorial (Fig. 1) [4]. Genetic predispositions most likely affect the role of the mucosal epithelium as a barrier, both structurally and functionally [4-7]. Immunity defects have long been known to be implicated in CRS, in particular for patients resistant to treatment [8]. Evidence for this includes the frequent occurrence of CRS in patients with common variable humoral immunodeficiency [9].

\footnotetext{
*Correspondence: desrosiers_martin@hotmail.com

${ }^{3}$ Centre de Recherche du Centre Hospitalier de I'Université de Montréal (CRCHUM), Université de Montréal, Montreal, QC, Canada

Full list of author information is available at the end of the article
}

Indirect support for implication of other immune deficiency states include a disequilibrium of $\mathrm{T}_{\mathrm{H}} 1 / \mathrm{T}_{\mathrm{H}} 2$, with a skewing towards stronger $\mathrm{T}_{\mathrm{H}} 2$ responses [10], aberrant TLR function in innate immunity [11], and chronic low-grade inflammation resulting from a constant feedforward loop of pro-inflammatory cytokines [12]. A role is emerging for the microbiome, particularly in a model governed by gene-environment interactions, which would have as permanent members dysbiotic bacteria that colonize the chronically-inflamed mucosa to keep the latter dysfunctional and incorrectly repaired [13]. This has opened the door to novel therapeutic approaches, such as topical therapy with probiotics [14], dietary modifications $[13,15]$ and use of antibiotics as immuno-modulators and microbiome-modifiers [16] are all currently being investigated in the clinical setting.
Main text
Auto-immunity in CRS
Conspicuously absent from these descriptions is the pos- sibility of a role for auto-immunity in CRS pathogenesis. This is somewhat surprising as auto-immunity is a ubiq- uitous culprit in pathologies affecting every other organ, thus it is likely that a similar phenomenon also occurs in CRS. Here we explore the auto-immune avenue, with a 


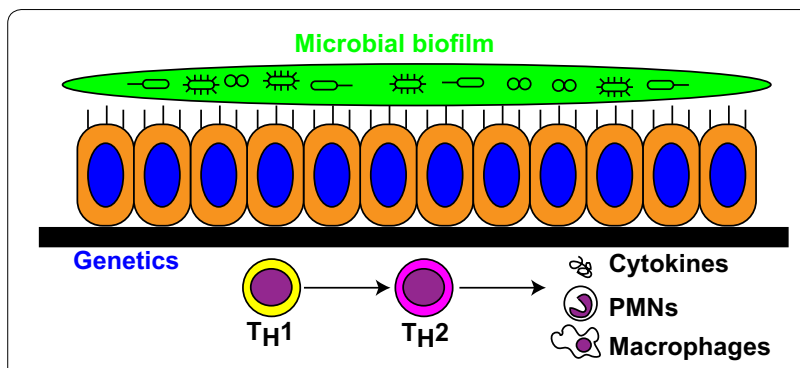

Fig. 1 Chronic rhinosinusitis (CRS) as a multifactorial disease. Genetic factors affect the mucosal epithelium barrier, both structurally and functionally. Immune factors induce a strong $\mathrm{T}_{\mathrm{H}} 2$ bias, which leads to cytokine production and impaired innate inflammatory response. Microbial factors promote a dysbiotic flora and biofilm formation. PMNs polymorphonuclear leukocytes

focus on comparison with chronic auto-immune conditions compromising the skin epidermal barrier.

\section{Evidence from immune complex disorders}

The deposition of auto-immune complexes in the sinus mucosa disrupting the sinus mucosal surface is already demonstrated in vasculitides [17]. Vasculitides which can present with sinusitis symptoms include granulomatosis with polyangiitis (GPA; formerly known as Wegener's granulomatosis) [18] and eosinophilic granulomatosis with polyangiitis (EGPA; Churg-Strauss Syndrome) [19]. Immune complexes formed by anti-neutrophil cytoplasmic auto-IgG antibodies (ANCA IgG) promote granuloma formation in the epithelium, effectively causing a chronically-inflamed permeable barrier [20, 21]. Although this constitutes an interesting autoimmune hypothesis for CRS, the severity of disease seen in these patients and the low prevalence of these disorders are not sufficient to account for the frequency of CRS. As an additional consideration, these two disorders differ markedly in their immunologic profile: GPA predominantly displays a $T_{H} 1$ response while immunity in EGPA is shifted towards $\mathrm{T}_{\mathrm{H}} 2$ cytokines, with both disorders showing $\mathrm{T}_{\mathrm{H}} 17$ profiles [22].

Given the pathophysiological differences between GPA and CRS, we postulate that other manifestations of autoimmunity are likely present in CRS. Since sinus mucosa represents an ectodermal barrier between internal microenvironments and external aggressors, CRS may share features with other barrier disorders, such as the skin.

\section{Auto-immunity and blistering skin disorders}

Auto-immune sub-epidermal blistering diseases of the skin epithelium include various acquired bullous disorders such as bullous pemphigoid, cicatricial pemphigoid, pemphigoid gestationis and epidermolysis bullosa acquisita [23]. Auto-antibodies are classically directed against components of the hemidesmosome-anchoring filament complexes or anchoring fibrils, which link the basement membrane to the basal keratinocyte layer via cytoskeletal elements [24]. These targeted proteins at the dermal-epidermal junction include laminins, collagens, integrins and other cell adhesion molecules [24].

Cicatricial, or mucous membrane, pemphigoid is a chronic auto-immune blistering disease that preferentially affects the oral and ocular mucosae, but can also affect the nasal mucosa and the genitalia [23]. Cicatricial pemphigoid shows the highest heterogeneity among auto-immune bullous conditions, with the identification of auto IgA and/or IgG targeting the $\alpha 6$ integrin subunit, $\beta 4$ integrin subunit, laminin 5 and/or BP180/collagen XVII $\alpha 1$ [25]. Pemphigoid, or herpes gestationis is a bullous eruption of the third trimester and immediate post-partum that extends from the umbilicus in a centrifugal direction [26]. In pemphigoid gestationis, a linear C3 deposition at the dermo-epidermal junctional is nearly always found, but auto IgG against BP180/collagen XVII and, less commonly, BP230 can be detected in a third of affected pregnancies [24, 26]. Similarly to other dermatoses of pregnancy, pemphigoid gestationis displays an immune imbalance towards a stronger $\mathrm{T}_{\mathrm{H}} 2$ response with concomitant depressed $\mathrm{T}_{\mathrm{H}} 1$ function [27]. Epidermolysis bullosa acquisita is characterized by recurring blisters on skin and mucosae arising from IgG autoimmunity against collagen VII [28, 29].

\section{Insights from bullous pemphigoid}

Studies from bullous pemphigoid (BP), a more common blistering disease of the elderly, have shed insights into the link between a dysbiotic flora and auto-immunity [30]. Auto IgG, and to a much lesser extent, auto IgA, against BP180/collagen XVII and BP230, a transmembrane protein of the hemidesmosal plaque, have been implicated in the pathogenesis of BP for many years [31, 32]. Recently, auto IgE antibodies have been consistently isolated from a subset of patients with BP, both at their dermal-epidermal junction [33, 34] and in their sera $[35,36]$. This led to the successful use of omalizumab, a humanized monoclonal that binds and inactivates free and membrane-bound IgE, to manage patients with standard treatment-refractory BP and elevated IgE titers [37, 38].

How does the presence of auto IgE in BP relate to CRS? First, IgE dysfunction and impairment of mast cell regulation and response are involved in various type I hypersensitivity reactions, such as asthma, allergic rhinitis, atopic dermatitis, and urticaria [39, 40]. Of note, CRS severity is strongly associated with the presence of asthma, nasal polyposis, aspirin allergy and atopy 
in general [41]. Serum IgE levels are elevated by 9- to 20 -fold in CRS patients (without or with nasal polyposis) [42]. Second, the use of omalizumab in refractory CRS patients with nasal polyposis has also improved symptomatology, significantly [43, 44] in some studies and non-significantly [45] in others. In the latest randomized clinical trial, this significant effect was present in patients with both allergic and non-allergic conditions [44], suggesting that the mechanisms of action is not simply limited to Type I hypersensitivity. Third, auto IgE antibodies can act in synergy with other auto-antibodies to mediate auto-immunity. In patients suffering from systemic lupus erythematous, auto-IgE antibodies, and the deposition of immune complexes containing auto-IgE, potentiate the effect of the more abundant auto-IgG antibodies ( 20 fold difference), leading to higher activation of innate inflammatory components, thus predicting a worse disease course [46]. Similarly, in CRS, auto-IgE antibodies could mediate the interplay between mucosal innate defenses, acquired auto-immunity, and microbial agents, despite their relative paucity (Fig. 2).

\section{BP180 auto-antibodies in CRS}

The discovery of autoantibodies in CRS patients is emerging. Anti-nuclear IgG and IgA autoantibody titers are elevated in CRS patients with nasal polyposis [47]. Recently, the discovery of elevated circulating levels of auto IgG against BP180/collagen XVII in CRS patients vs. healthy patients bring the link with bullous pemphigoid back into the spotlight [48]. However, deposition of these autoantibodies at the dermal-epidermal junction has been absent from the nasal mucosa of CRS patients, in stark contrast with BP in which it is pathogenic [48]. Nevertheless, auto-immunity appears to play an important role in CRS, and similarities to BP and other acquired skin bullous dermatoses are numerous.

\section{Genetics, CRS and skin bullous conditions}

Other links to epithelial blistering disorders are suggested by genome-wide association studies (GWAS) of refractory CRS, in which several of the most common gene polymorphisms in CRS patients code for basement membrane and extra-cellular matrix proteins, including the laminins $[6,49]$. Other polymorphisms associated with CRS are found in collagen- and keratin-interacting genes [49]; the complete absence of these genes and related genes as well as aberrant gene expression can lead to some of the rare hereditary epidermolysis bullosa genodermatoses [50]. Taken together, these findings suggest that interference with epithelial structure leading to epithelial blistering disorders in skin may mimic changes seen in CRS.

\section{CRS similarities to other skin conditions}

In addition to skin bullous diseases, other skin conditions may yield insight into the pathophysiology of CRS. In chronic urticaria, dysregulated cellular function and autoantibodies targeting directly IgE or their receptor on mast cells lead to the degranulation of mast cells and subsequent release of pre-formed pro-inflammatory

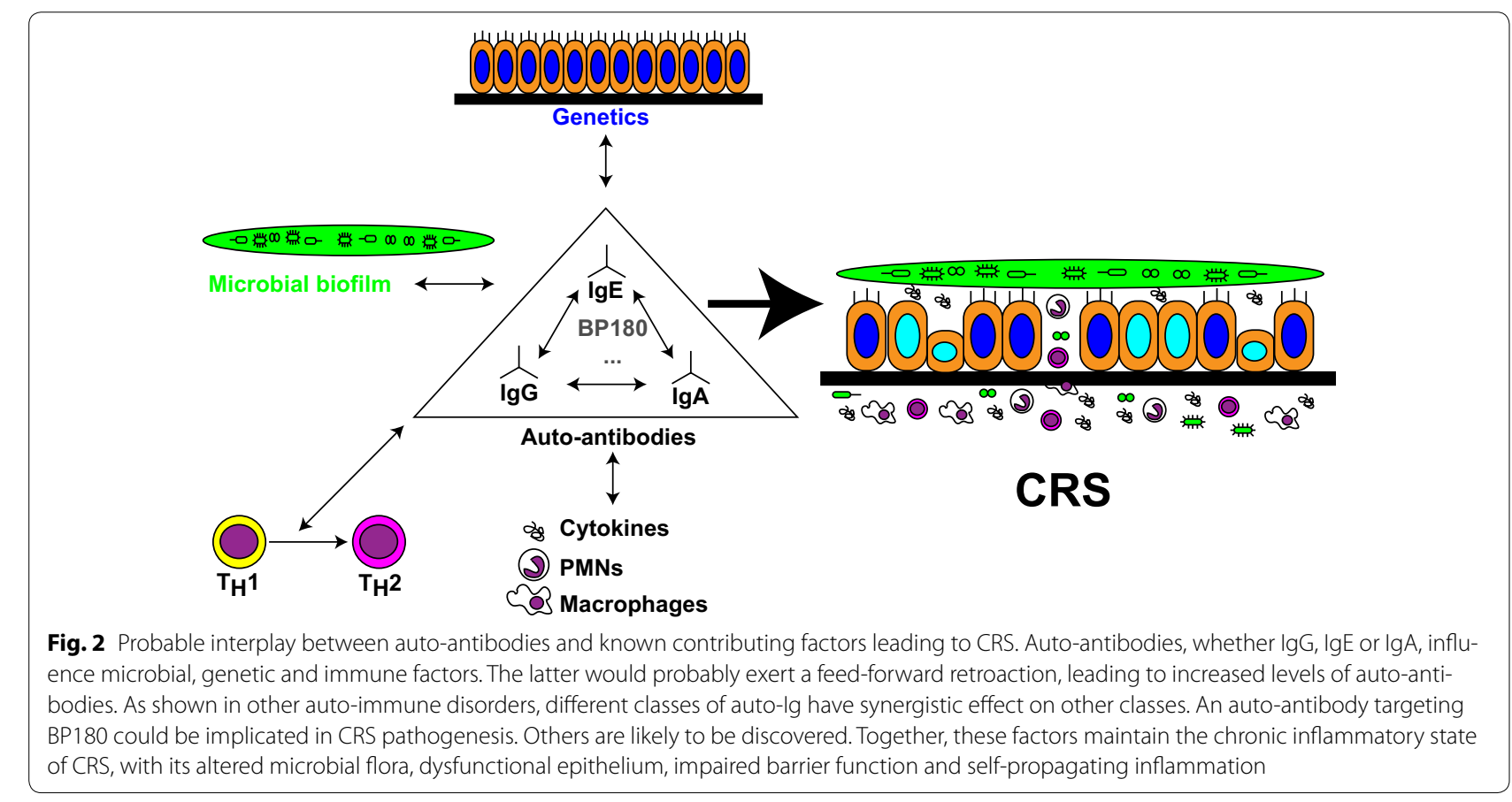


cytokines [51]. In CRS with nasal polyposis, mast cells in the epithelium and glandular structures are increased in number and are producing abnormally-high quantities of proteases, thus contributing to the chronic inflammation and lack of complete repair [52]. Circulating auto-IgE antibodies have also been detected in chronic urticaria patients [53].

\section{Conclusion}

CRS likely arises from the interaction of genetic, immunological and microbial factors. This concept may evolve to incorporate a contribution from auto immune disorders. While experience with autoimmunity in CRS is still very limited, insights may be drawn from experience with skin epidermal disorders. Notably, in skin, auto-immunity in epidermis-basement membrane unit renders the epidermis dysfunctional and more permeable to surface pathogens, which may penetrate into the dermis, enabling the colonization by a dysbiotic flora that maintains a chronic inflammation state. This contributes to the secondary mucosal changes seen in skin disorders. These concepts resonate well with the disease process observed in CRS. The role of auto-immunity in CRS, especially in refractory cases, appears compelling. Given the aforementioned similarities between sub-epidermal bullous dermatoses, focusing on the basal keratinocyte-hemidesmosome-cytoskeleton-basal membrane interface might reveal additional mechanistic information. Additionally, it is important to recognize that not all autoimmune actors are IgG auto-antibodies, and that IgA and IgE auto-antibodies may be more common than expected. Assessment for these should also be performed. As previously mentioned in the case of anti-BP180 in CRS [48], it is important to distinguish circulating auto-antibodies from those bound to the epithelium as these are probably significant for the maintenance of the disease. Nevertheless, dosing circulating auto-antibodies may serve as a proxy for detecting auto-immunity. As in $\mathrm{BP}$ and chronic urticaria, refractory CRS might also feature auto-IgE antibodies.

Suggestions for further studies include (1) verifying the presence of other circulating auto-antibodies targeting the dermal-epidermal junction and the hemidesmosome plaque in CRS patients, and (2) determining the presence of auto-antibodies on sinus biopsies/tissues and nasal polyps from CRS patients using dermato-histopathological techniques.

On the clinical side, implications of these findings are twofold. First, investigation of CRS should include the possibility of auto-immunity. Second, clinicians may have to consider biological and targeted therapies aimed at decreasing auto-immunity in refractory CRS patients. Experience with those treatment regimens from diseases involving other body systems should come in handy for CRS. However, therapeutic agents used in other disorders will require prospective assessment prior to clinical deployment.

\section{Authors' contributions}

$\mathrm{PL}, \mathrm{HC}, \mathrm{BC}$ and MD wrote the manuscript. All authors read and approved the final manuscript.

\section{Author details}

${ }^{1}$ Faculté de Médecine, Université de Montréal, Montreal, QC, Canada. ${ }^{2}$ Centre Hospitalier de I'Université de Montréal (CHUM), Université de Montréal, Montreal, QC, Canada. ${ }^{3}$ Centre de Recherche du Centre Hospitalier de I'Université de Montréal (CRCHUM), Université de Montréal, Montreal, QC, Canada.

\section{Competing interests}

The authors declare that they have no competing interests.

Received: 8 June 2016 Accepted: 13 July 2016

Published online: 05 August 2016

\section{References}

1. Adams PF, Hendershot GE, Marano MA, Centers for Disease Control, Prevention/ National Center for Health Statistics. Current estimates from the National Health Interview Survey, 1996. Vital Health Stat 10. 1996;1999(200):1-203.

2. Rudmik L, Soler ZM, Smith TL, Mace JC, Schlosser RJ, DeConde AS. Effect of continued medical therapy on productivity costs for refractory chronic rhinosinusitis. JAMA Otolaryngol Head Neck Surg. 2015;141(11):969-73.

3. Caulley L, Thavorn K, Rudmik L, Cameron C, Kilty SJ. Direct costs of adult chronic rhinosinusitis by using 4 methods of estimation: results of the US Medical Expenditure Panel Survey. J Allergy Clin Immunol. 2015;136(6):1517-22.

4. Hsu J, Avila PC, Kern RC, Hayes MG, Schleimer RP, Pinto JM. Genetics of chronic rhinosinusitis: state of the field and directions forward. J Allergy Clin Immunol. 2013;131(4):977-93.

5. Castano R, Bosse Y, Endam LM, Filali-Mouhim A, Desrosiers M. C-MET pathway involvement in chronic rhinosinusitis: a genetic association analysis. Otolaryngol Head Neck Surg. 2010;142(5):665-71.

6. Bosse Y, Bacot F, Montpetit A, Rung J, Qu HQ, Engert JC, Polychronakos C, Hudson TJ, Froguel P, Sladek R, et al. Identification of susceptibility genes for complex diseases using pooling-based genome-wide association scans. Hum Genet. 2009;125(3):305-18.

7. Tournas A, Mfuna L, Bosse Y, Filali-Mouhim A, Grenier JP, Desrosiers M. A pooling-based genome-wide association study implicates the p73 gene in chronic rhinosinusitis. J Otolaryngol Head Neck Surg. 2010;39(2):188-95.

8. Shapiro GG, Virant FS, Furukawa CT, Pierson WE, Bierman CW. Immunologic defects in patients with refractory sinusitis. Pediatrics. 1991;87(3):311-6.

9. Srinivasa BT, Alizadehfar R, Desrosiers M, Shuster J, Pai NP, Tsoukas CM Adult primary immune deficiency: what are we missing? Am J Med. 2012;125(8):779-86.

10. Van Zele T, Claeys S, Gevaert P, Van Maele G, Holtappels G, Van Cauwenberge $P$, Bachert $C$. Differentiation of chronic sinus diseases by measurement of inflammatory mediators. Allergy. 2006;61(11):1280-9.

11. Lane AP, Truong-Tran QA, Schleimer RP. Altered expression of genes associated with innate immunity and inflammation in recalcitrant rhinosinusitis with polyps. Am J Rhinol. 2006;20(2):138-44.

12. Van Crombruggen $K$, Zhang N, Gevaert $P$, Tomassen $P$, Bachert C. Pathogenesis of chronic rhinosinusitis: inflammation. J Allergy Clin Immunol. 2011;128(4):728-32

13. Kramer MF, Heath MD. Probiotics in the treatment of chronic rhinoconjunctivitis and chronic rhinosinusitis. J Allergy. 2014;2014:983635.

14. Cope EK, Lynch SV. Novel microbiome-based therapeutics for chronic rhinosinusitis. Curr Allergy Asthma Rep. 2015;15(3):504. 
15. Nayan S, Maby A, Endam LM, Desrosiers M. Dietary modifications for refractory chronic rhinosinusitis? Manipulating diet for the modulation of inflammation. Am J Rhinol Allergy. 2015;29(6):170-4.

16. Harvey RJ, Wallwork BD, Lund VJ. Anti-inflammatory effects of macrolides: applications in chronic rhinosinusitis. Immunol Allergy Clin North Am. 2009;29(4):689-703

17. Montone KT. The molecular genetics of inflammatory, autoimmune, and infectious diseases of the sinonasal tract: a review. Arch Pathol Lab Med. 2014;138(6):745-53.

18. Tarabishy AB, Schulte M, Papaliodis GN, Hoffman GS. Wegener's granulomatosis: clinical manifestations, differential diagnosis, and management of ocular and systemic disease. Surv Ophthalmol. 2010;55(5):429-44.

19. Bacciu A, Bacciu S, Mercante G, Ingegnoli F, Grasselli C, Vaglio A, Pasanisi E, Vincenti V, Garini G, Ronda N, et al. Ear, nose and throat manifestations of Churg-Strauss syndrome. Acta Otolaryngol. 2006;126(5):503-9.

20. van der Woude FJ, Rasmussen N, Lobatto S, Wiik A, Permin H, van Es LA, van der Giessen M, van der Hem GK, The TH. Autoantibodies against neutrophils and monocytes: tool for diagnosis and marker of disease activity in Wegener's granulomatosis. Lancet. 1985;1 (8426):425-9.

21. Seo P, Stone JH. The antineutrophil cytoplasmic antibody-associated vasculitides. Am J Med. 2004;117(1):39-50.

22. Fagin U, Csernok E, Muller A, Pitann S, Fazio J, Krause K, Bremer P, WipflerFreissmuth E, Moosig F, Gross WL, et al. Distinct proteinase 3-induced cytokine patterns in Wegener's granulomatosis, Churg-Strauss syndrome, and healthy controls. Clin Exp Rheumatol. 2011;29(1 Suppl 64):S57-62.

23. Olasz EB, Yancey KB. Bullous pemphigoid and related subepidermal autoimmune blistering diseases. Curr Dir Autoimmun. 2008;10:141-66.

24. Mihai S, Sitaru C. Immunopathology and molecular diagnosis of autoimmune bullous diseases. J Cell Mol Med. 2007;11(3):462-81.

25. Rashid KA, Gurcan HM, Ahmed AR. Antigen specificity in subsets of mucous membrane pemphigoid. J Invest Dermatol. 2006;126(12):2631-6.

26. Shimanovich I, Brocker EB, Zillikens D. Pemphigoid gestationis: new insights into the pathogenesis lead to novel diagnostic tools. BJOG. 2002;109(9):970-6.

27. Fabbri P, Caproni M, Berti S, Bianchi B, Amato L, De Pita O, Frezzolini A. The role of T lymphocytes and cytokines in the pathogenesis of pemphigoid gestationis. Br J Dermatol. 2003;148(6):1141-8.

28. Woodley DT, Briggaman RA, O'Keefe EJ, Inman AO, Queen LL, Gammon WR. Identification of the skin basement-membrane autoantigen in epidermolysis bullosa acquisita. N Engl J Med. 1984;310(16):1007-13.

29. Woodley DT, Burgeson RE, Lunstrum G, Bruckner-Tuderman L, Reese MJ, Briggaman RA. Epidermolysis bullosa acquisita antigen is the globular carboxyl terminus of type VII procollagen. J Clin Investig. 1988;81(3):683-7.

30. Ujiie H. IgE autoantibodies in bullous pemphigoid: supporting role, or leading player? J Dermatol Sci. 2015:78(1):5-10.

31. Cozzani E, Drosera M, Parodi A, Carrozzo M, Gandolfo S, Rebora A. Frequency of $\lg A$ antibodies in pemphigus, bullous pemphigoid and mucous membrane pemphigoid. Acta Dermato-Venereologica. 2004;84(5):381-4.

32. Schmidt E, Zillikens D. Pemphigoid diseases. Lancet. 2013;381(9863):320-32.

33. Kamiya K, Aoyama Y, Noda K, Miyake T, Yamaguchi M, Hamada T, Tokura Y, Iwatsuki K. Possible correlation of IgE autoantibody to BP180 with disease activity in bullous pemphigoid. J Dermatol Sci. 2015;78(1):77-9.

34. Moriuchi R, Nishie W, Ujiie H, Natsuga K, Shimizu H. In vivo analysis of IgE autoantibodies in bullous pemphigoid: a study of 100 cases. J Dermatol Sci. 2015;78(1):21-5.
35. Delaporte E, Dubost-Brama A, Ghohestani R, Nicolas JF, Neyrinck JL, Bergoend $\mathrm{H}$, Janin A, Capron M. IgE autoantibodies directed against the major bullous pemphigoid antigen in patients with a severe form of pemphigoid. J Immunol. 1996;157(8):3642-7.

36. Ishiura N, Fujimoto M, Watanabe R, Nakashima H, Kuwano Y, Yazawa N, Echigo T, Okochi H, Tamaki K. Serum levels of IgE anti-BP180 and antiBP230 autoantibodies in patients with bullous pemphigoid. J Dermatol Sci. 2008;49(2):153-61.

37. London VA, Kim GH, Fairley JA, Woodley DT. Successful treatment of bullous pemphigoid with omalizumab. Arch Dermatol. 2012;148(11):1241-3.

38. Yu KK, Crew AB, Messingham KA, Fairley JA, Woodley DT. Omalizumab therapy for bullous pemphigoid. J Am Acad Dermatol. 2014;71(3):468-74.

39. Gould HJ, Sutton BJ. IgE in allergy and asthma today. Nat Rev Immunol. 2008;8(3):205-17

40. Holgate ST. Pathogenesis of asthma. Clin Exp Allergy. 2008;38(6):872-97.

41. Pearlman AN, Chandra RK, Chang D, Conley DB, Tripathi-Peters A, Grammer LC, Schleimer RT, Kern RC. Relationships between severity of chronic rhinosinusitis and nasal polyposis, asthma, and atopy. Am J Rhinol Allergy. 2009;23(2):145-8.

42. Chao PZ, Hsieh MS, Lee FP, Chen SY, Cheng CW, Chang HW, Lin YT, Ting $\mathrm{LL}$, Lin YF, Chen CH. Serum level of interleukin-21 is elevated in chronic rhinosinusitis. Am J Rhinol Allergy. 2015;29(1):e1-6.

43. Penn R, Mikula S. The role of anti-lgE immunoglobulin therapy in nasal polyposis: a pilot study. Am J Rhinol. 2007;21(4):428-32.

44. Gevaert P, Calus L, Van Zele T, Blomme K, De Ruyck N, Bauters W, Hellings P, Brusselle G, De Bacquer D, van Cauwenberge P, et al. Omalizumab is effective in allergic and nonallergic patients with nasal polyps and asthma. J Allergy Clin Immunol. 2013;131(1):110-6.

45. Pinto JM, Mehta N, DiTineo M, Wang J, Baroody FM, Naclerio RM. A randomized, double-blind, placebo-controlled trial of anti-lgE for chronic rhinosinusitis. Rhinology. 2010;48(3):318-24.

46. Henault J, Riggs JM, Karnell JL, Liarski VM, Li J, Shirinian L, Xu L, Casey KA, Smith MA, Khatry DB, et al. Self-reactive IgE exacerbates interferon responses associated with autoimmunity. Nat Immunol. 2016;17(2):196-203.

47. Tan BK, Li QZ, Suh L, Kato A, Conley DB, Chandra RK, Zhou J, Norton J, Carter R, Hinchcliff $M$, et al. Evidence for intranasal antinuclear autoantibodies in patients with chronic rhinosinusitis with nasal polyps. J Allergy Clin Immunol. 2011;128(6):1198-206.

48. Jeffe JS, Seshadri S, Hamill KJ, Huang JH, Carter R, Suh L, Hulse KE, Norton J, Conley DB, Chandra RK, et al. A role for anti-BP180 autoantibodies in chronic rhinosinusitis. Laryngoscope. 2013;123(9):2104-11.

49. Mfuna-Endam L, Zhang Y, Desrosiers MY. Genetics of rhinosinusitis. Curr Allergy Asthma Rep. 2011;11(3):236-46.

50. Has C, Bruckner-Tuderman L. The genetics of skin fragility. Annu Rev Genomics Hum Genet. 2014;15:245-68.

51. Chan YC, Ramadani F, Santos AF, Pillai P, Ohm-Laursen L, Harper CE, Fang C, Dodev TS, Wu SY, Ying S, et al. "Auto-anti-IgE": naturally occurring IgG anti-IgE antibodies may inhibit allergen-induced basophil activation. J Allergy Clin Immunol. 2014;134(6):1394-401.

52. Takabayashi T, Kato A, Peters AT, Suh LA, Carter R, Norton J, Grammer LC, Tan BK, Chandra RK, Conley DB, Kern RC, et al. Glandular mast cells with distinct phenotype are highly elevated in chronic rhinosinusitis with nasal polyps. J Allergy Clin Immunol. 2012;130(2):410-20.

53. Altrichter S, Peter HJ, Pisarevskaja D, Metz M, Martus P, Maurer M. IgE mediated autoallergy against thyroid peroxidase-a novel pathomechanism of chronic spontaneous urticaria? PLoS ONE. 2011;6(4):e14794. 